\title{
Para onde orientam estudos sobre Pensamento Algébrico e Lesson Study? Caracterização de pesquisas com professores dos anos iniciais (2009-2019)
}

\author{
Where do studies on Algebraic Thinking and Lesson Study take us? \\ Characterization of research with teachers from the early years of Elementary \\ School (2009-2019)
}

Beatriz Sarto

Klinger Teodoro Ciríaco

Resumo: Afirmamos a importância de perspectivas do trabalho, em regime de colaboração, com professores que ensinam Matemática na Educação Básica, particularmente no ciclo da alfabetização frente à inserção da unidade temática Álgebra no currículo dos Anos Iniciais. $\mathrm{O}$ artigo baseia-se em revisão de literatura, com mapeamento de teses e dissertações, voltada à teorização dos estudos desenvolvidos na última década (2009 a 2019) que abarcaram os descritores Pensamento Algébrico e Lesson Study em programas de pós-graduação da área de Educação e Ensino, situados no Estado de São Paulo. A análise dos diferentes estudos localizados no contexto paulista desvelou indícios relevantes à indicadores futuros, os quais possibilitaram-nos aprimorar a atividade de extensão e pesquisa que desenvolvemos em 2019. A aproximação com as experiências anteriores sinaliza para necessidade de constituir espaços de formação, centrados na escola, que possibilitem a instrumentalização docente no que respeita atributos definidores do desenvolvimento do pensamento algébrico com as crianças.

Palavras-chave: Mapeamento de Teses e Dissertações. Pensamento Algébrico. Lesson Study. Anos Iniciais.

Abstract: We affirm the importance of working perspectives, in collaboration, with teachers who teach Mathematics in Basic Education, particularly in the 1st, 2nd and 3rd grades, given the insertion of the thematic unit Algebra in the curriculum of the Early Years. The article is based on a wide literature review, with mapping of theses and dissertations, aimed at theorizing the studies developed in the last decade (2009 to 2019) that encompassed the descriptors Algebraic Thinking and Lesson Study in post- graduation in the Education and Teaching area of the State of São Paulo, Brazil. The analysis of the different studies located in the São Paulo context revealed relevant evidence for future indicators, which enabled us to improve the

Beatriz Sarto Licencianda em Pedagogia pela Universidade Federal de São Carlos (UFSCar), campus São Carlos. São Paulo, Brasil. iD orcid.org/0000-0001-6071-4417 $\triangle$ sartobia@hotmail.com

Klinger Teodoro Ciríaco Doutor em Educação. Professor da Universidade Federal de São Carlos (UFSCar), campus São Carlos. Professor do Programa de Pós-Graduação em Educação Matemática da Universidade Federal de Mato Grosso do Sul (UFMS). São Paulo, Brasil. (iD) orcid.org/0000-0003-1694-851X $\triangle$ ciriacoklinger@gmail.com

Recebido em 20/06/2020 Aceito em 13/07/2020 Publicado em 15/07/2020 extension and research activity that we developed in 2019. The approximation with previous experiences signals the need to establish training spaces, centered on the school, which enable the instrumentalization of teachers in terms of the defining attributes of the development of algebraic thinking with children.

Keywords: Mapping of Theses and Dissertations. Algebraic Thinking. Lesson Study. Years of Elementary School. 


\section{Introdução}

Intencionamos, com o compartilhamento deste paper ${ }^{1}$, dar visibilidade aos trabalhos defendidos em programas de pós-graduação stricto sensu — mestrado e doutorado — da região Sudeste do Brasil, especificamente de universidades situadas no Estado de São Paulo. Reside, no escopo central dessa pretensão, o interesse particular da constituição de um grupo de trabalho, na perspectiva do desenvolvimento do pensamento algébrico no ciclo da alfabetização, mediado por práticas colaborativas que incorporam a metodologia de formação continuada lesson study, por isso os descritores adotados no mapeamento das teses e dissertações foram Pensamento Algébrico e Lesson Study, respectivamente. 0 trabalho ${ }^{2}$ empreendeu esforços em levantar uma discussão pautada nos resultados de investigações desenvolvidas nos últimos dez anos acerca da temática, a qual constitui-se objeto direto de produção de dados do trabalho de conclusão de curso em Pedagogia da primeira autora, orientado pelo segundo autor.

A revisão posta em apreciação inclui, também, a conceituação dos termos, bem como incorpora o referencial teórico que adotamos quando nos referimos ao estudo que coordenamos em 2019 no âmbito de um projeto de extensão em uma escola parceira da rede estadual de educação em São Carlos (SP), isso por nos dedicarmos a estudar o assunto com um grupo de professoras de $1^{\circ}$ ao $3^{\circ}$ ano do Ensino Fundamental.

Sendo assim, o artigo ora apresentado não pretende esgotar a problematização do assunto de forma definitiva, mas sim, abrir espaço ao debate devido à extensão da produção do conhecimento na área. Assim, apresenta dados de estudos considerados metodologicamente sólidos e teoricamente relevantes que foram reunidos, via mapeamento nos programas paulistas, com a intenção de resumir/divulgar, ao menos em parte, o conhecimento produzido sobre a importância da inclusão do pensamento algébrico nos primeiros anos e a incorporação da metodologia estudos de aula no campo da formação continuada de professores que ensinam Matemática, haja vista que defendemos, dadas as especificidades deste processo, ser este um caminho rico e promissor a ser explorado em contextos de mudança curricular como a que estamos a vivenciar desde que a Álgebra passou a figurar objeto matemático nos Anos Iniciais

\footnotetext{
10 presente artigo será apresentado na Universidade Federal de São Carlos (UFSCar), campus São Carlos, como objeto de apreciação para integração dos créditos curriculares do Trabalho de Conclusão de Curso (TCC) no $10^{\circ}$ semestre da Licenciatura em Pedagogia da primeira autora.

2 Referimo-nos à atividade "Lesson Study e o Desenvolvimento do Pensamento Algébrico no Ciclo da Alfabetização em uma Escola Pública de São Carlos-SP" financiada pela Pró-Reitoria de Extensão (ProEx) da Universidade Federal de São Carlos (UFSCar), campus São Carlos.
} 
com a publicação da Base Nacional Curricular Comum — BNCC (BRASIL, 2017).

A organização e apresentação que se coloca em apreciação segue, além desta introdução, um raciocínio que busca: a) problematizar desafios postos ao professor pedagogo, frente a inserção do pensamento algébrico nos primeiros anos e, ao mesmo tempo, levantar indicadores da possibilidade de ações de formação continuada em lesson study como alternativa para o momento que estamos a vivenciar; b) descrever, de forma detalhada, o processo de mapeamento dos trabalhos da última década nas bases de indexação dos programas de pósgraduação; c) apresentação dos objetivos, referenciais teóricos e metodológicos, principais resultados e suas conclusões; e, por fim, d) algumas considerações no sentido de responder a questão do título deste artigo: para onde os estudos nos orientam?

\section{A inserção do pensamento algébrico nos Anos Iniciais e a formação/prática do professor que ensina Matemática em lesson study}

No Brasil, anteriormente ao ano de 2018, os currículos de Matemática para os Anos Iniciais eram norteados e/ou orientados a partir dos dizeres enunciados nos Parâmetros Curriculares Nacionais para o Ensino Fundamental - PCN (BRASIL, 1997). Nos PCN, a Matemática nos primeiros anos, particularmente no ciclo de alfabetização, destinava-se ao trabalho com blocos de conteúdos, sendo Números e Operações; Espaço e Forma; Grandezas e Medidas e Tratamento da Informação. A menção sobre Álgebra era destinada apenas após a finalização da etapa que hoje compreende-se como Anos Iniciais. Sendo assim, podemos perceber que, embora o $\mathrm{PCN}$ do $1^{\circ}$ e $2^{\circ}$ ciclo não façam menção à Álgebra, esta se fazia presente no bloco de conteúdo Números e Operações por meio de algumas propriedades, contudo, pela falta de conhecimento em relação ao tema, o qual não era objeto de trabalho do professor pedagogo, os conhecimentos ligados a processos algébricos, de forma declarada explicitamente, destinavam-se, naquele período, ao trabalho do professor especialista, sendo este, então, 0 licenciado em Matemática.

Seguindo a lógica de postulados teóricos de autores como Blanton e Kaput (2005), Schliemann, Carraher e Brizuela (2007) e de documentos estadunidenses e europeus: Principles and Standards for School Mathmatics (2000), publicado pelo National Council of Teachers Mathematics e outros, a inserção do pensamento algébrico nos primeiros anos escolares passou a ser uma realidade no cenário educacional brasileiro, a partir de 2018, com a apresentação da 
Base Nacional Comum Curricular (BNCC).

Os currículos prescritos, até então, priorizavam a Aritmética, ou seja, o trabalho com números e operações, sem variáveis, enxergando a aprendizagem do pensamento aritmético como base para a aprendizagem da Álgebra, posteriormente. Isso porque tinha-se, claramente, a compreensão de que

se a construção dos conceitos aritméticos não for priorizada, é possível que os estudantes encontrem dificuldades em aprender os conceitos relacionados à Álgebra, porquanto a Aritmética tem sido tomada como um alicerce que dá suporte para a aprendizagem da Álgebra (BEZERRA, 2010 apud LIMA e BIANCHINI, 2017, p. 200).

Essa ideia que permeia os PCN se dá pela transposição didática, ou seja, a escolha das instituições de apresentar um currículo prescrito com uma ordem determinada dos conteúdos, e também pela ideia de ordem pedagógico-psicológica, que é a limitação dos processos de aprendizagem por estágios gerais de desenvolvimento. Portanto, nesta concepção de aprendizagem, o estudante só é capaz de aprender o conteúdo proposto pelo professor quando adquire algumas condições pré-estabelecidas (FALCÃO, 2003). Existiria, então, uma ordem no currículo brasileiro para apresentação de conteúdos no Ensino Fundamental, nesse caso em específico, "a álgebra deve "esperar" para ser apresentada depois que os alunos já tiverem conseguido o domínio de alguns princípios aritméticos" (FALCÃO, 2003, p. 28).

Recomendações da literatura especializada na temática (FIORENTINI, MIORIM e MIGUEL, 1993; CANAVARRO, 2007) vêm mostrar o contrário: Álgebra e Aritmética podem ser aprendidas simultaneamente e devem dar suporte uma à outra, sem ser necessário que a linguagem simbólica formal da Álgebra seja inserida logo nos primeiros anos, para que desta forma os estudantes tenham mais facilidade no decorrer da escolarização, é o que sugere 0 desenvolvimento do pensamento algébrico nos Anos Iniciais. Em nosso país, o reconhecimento deste campo, com sua inserção no início da Educação Básica, teve influência da propositura do que se colocou nos dizeres da BNCC (2017), recentemente e ainda tem gerado muitas dúvidas sobre seus significados tanto aos professores em exercício quanto aos programas de formação inicial.

A Base Nacional Comum Curricular (BRASIL, 2017), documento que se intitula orientador dos currículos em todo território nacional, se divide em unidades temáticas que na área da Matemática são cinco: Grandeza e Medidas; Números; Probabilidade e Estatística; Geometria; e Álgebra. Ao inserir a unidade Álgebra, compreende-a como 
o desenvolvimento de um tipo especial de pensamento - pensamento algébrico que é essencial para utilizar modelos matemáticos na compreensão, representação e análise de relações quantitativas de grandezas e, também, de situações e estruturas matemáticas, fazendo uso de letras e outros símbolos (BRASIL, 2017, p. 270).

Especificamente, para os Anos Iniciais, prescreve ser

\begin{abstract}
imprescindivel que algumas dimensões do trabalho com a álgebra estejam presentes nos processos de ensino e aprendizagem desde o Ensino Fundamental - Anos Iniciais, como as ideias de regularidade, generalização de padrões e propriedades da igualdade. No entanto, nessa fase, não se propõe o uso de letras para expressar regularidades, por mais simples que sejam (BRASIL, 2017, p. 270).
\end{abstract}

Diante disso, a BNCC (2017) destaca aspectos de modo que, aparentemente, se desenvolva a Álgebra em uma relação com conteúdos matemáticos presentes em outras unidades temáticas, a exemplo de Números. Contudo, cabe ressaltar que os dizeres do documento não são claros; desconsideram estudos recentes da área e se apresentam nos moldes de um ensino tecnicista, com uma visão implícita de professores e estudantes como meros executores e receptores de um currículo que lhes é apresentado sem incorporação de elementos característicos da realidade em que se vive, sem discussões do contexto social. Na leitura que fazemos, na nossa interpretação, é preciso desenvolver uma percepção crítica em relação ao que se prevê, isso porque, da forma como se coloca, desenvolver o pensamento algébrico com crianças dos Anos Inicias, se levarmos em consideração puramente o documento, podemos cair em uma supervalorização da linguagem simbólica e, ao invés de explorar as propriedades algébricas como aliadas no processo de compreensão dos significados matemáticos, esta pode vir a ser mais um fator contributivo para os índices insatisfatórios de proficiência que temos acompanhado em avaliações externas nos últimos anos. Em outras palavras, como colocam Fiorentini, Miorim e Miguel (1993), torna-se preciso repensar a educação algébrica e o papel que esta desempenha na história do pensamento da humanidade.

Adotamos, portanto, em nosso contexto de estudo, a seguinte definição de pensamento algébrico:

processo pelo qual os alunos generalizam ideias matemáticas a partir de um conjunto de casos particulares, estabelecem essas generalizações através de discurso argumentativo, e expressam-nas de formas progressivamente mais formais e adequadas à sua idade (BLANTON e KAPUT, 2005 apud CANAVARRO, 2007, p. 87).

Na concepção expressa, o pensamento algébrico pode ser desenvolvido de diversas 
formas no ciclo da alfabetização ao se tomar como ponto de partida ideias de regularidade, generalização de padrões e propriedades da igualdade. A pesquisadora portuguesa da Universidade de Évora, Ana Paula Canavarro, ao discutir sobre a temática, apresenta algumas possibilidades de tarefas como a resolução de problemas quando se trata da generalização de padrões, o que podemos observar no caso abaixo:

\begin{abstract}
Quantos telefonemas? Cinco alunos ganharam um concurso. Quando souberam da notícia, telefonaram uns aos outros a felicitarem-se. Descobre quantas chamadas tiveram que fazer os cinco amigos para se felicitarem todos entre si... E se fossem seis amigos, quantas chamadas fariam? E se fossem sete amigos, quantas chamadas fariam? Consegues descobrir alguma regra para qualquer número de amigos? (CANAVARRO, 2007, p. 82).
\end{abstract}

A proposta que nos é apresentada pela autora, como forma de exploração da generalização para fundamentar e definir pensamento algébrico, incorpora pressupostos teóricos de Schliemann, Carraher e Brizuela (2007), para os quais o ato de generalizar está no "coração" deste tipo de pensamento. Em um contexto de problematização desta tarefa, no texto original de Canavarro (2007), à medida que as crianças se envolvem na produção de significados para resolver o problema, levantam hipóteses que permitem localizar um padrão de resolução que caberá como "aplicação", via de regra, para se solucionar outras quantidades de ligações, por isso a pergunta do professor "e se fossem... mais amigos", representa formas de generalizar as ideias matemáticas postas em apreciação pelos estudantes. Outras possibilidades, podem ocorrer ainda em tarefas que envolvem a exploração da tabuada, sempre incentivando que os estudantes façam registros do caminho de sua resolução (modo de pensar) para a resposta obtida. No princípio multiplicativo, implícito nesta, o primeiro número "dita" quantas vezes o segundo se multiplicará e/ou se "repetirá" (3 vezes 6, por exemplo).

Nos exemplos expostos, de acordo com Canavarro (2007, p. 86), as produções escritas e conclusões das crianças poderão revelar que

\footnotetext{
identificaram a estrutura matemática da situação em análise; Estabeleceram relações numéricas entre as duas variáveis em causa; Generalizaram uma regra para a determinação de qualquer termo da sequência, em linguagem natural, justificando-a; Expressaram a generalização de duas formas distintas, por recorrência e através do termo geral.
}

Reportando-nos ao cenário brasileiro, Nacarato e Custódio (2018) mostram no livro 0 Desenvolvimento do Pensamento Algébrico na Educação Básica: Compartilhando Propostas de 
Sala de Aula com o Professor que Ensina (Ensinará) Matemática, com o apoio do Grupo Colaborativo em Matemática - GRUCOMAT, possibilidades de tarefas sobre pensamento algébrico e experiências de docentes exitosas com este campo. Santos, Luvison e Moreira (2018), na segunda parte da referida obra, ressaltam a importância da intencionalidade no processo educativo, enfatizando uma postura problematizadora do professor, que deverá selecionar tarefas potencializadoras e planejar a melhor forma para explorá-las.

No que respeita ao desenvolvimento da percepção de regularidades, Santos, Luvison e Moreira (2018) propõem tarefas com sequências, em que o objetivo deve ser a identificação do "segredo/motivo" pelo estudante. Tais tarefas devem levar em conta as vivências anteriores das crianças e, por isso, é importante a discussão dos diferentes modos de resolução que possivelmente serão apresentados. As sequências podem ser construídas de diferentes formas: com cores, imagens, desenhos, entre outras opções que o professor que ensina Matemática considerar mais pertinente como, por exemplo, tampas de garrafas ou o próprio corpo para que os estudantes tenham a possibilidade de criação e, não apenas, resolver. Especificamente acerca do ciclo da alfabetização, podemos citar o exemplo apresentado pelos autores:

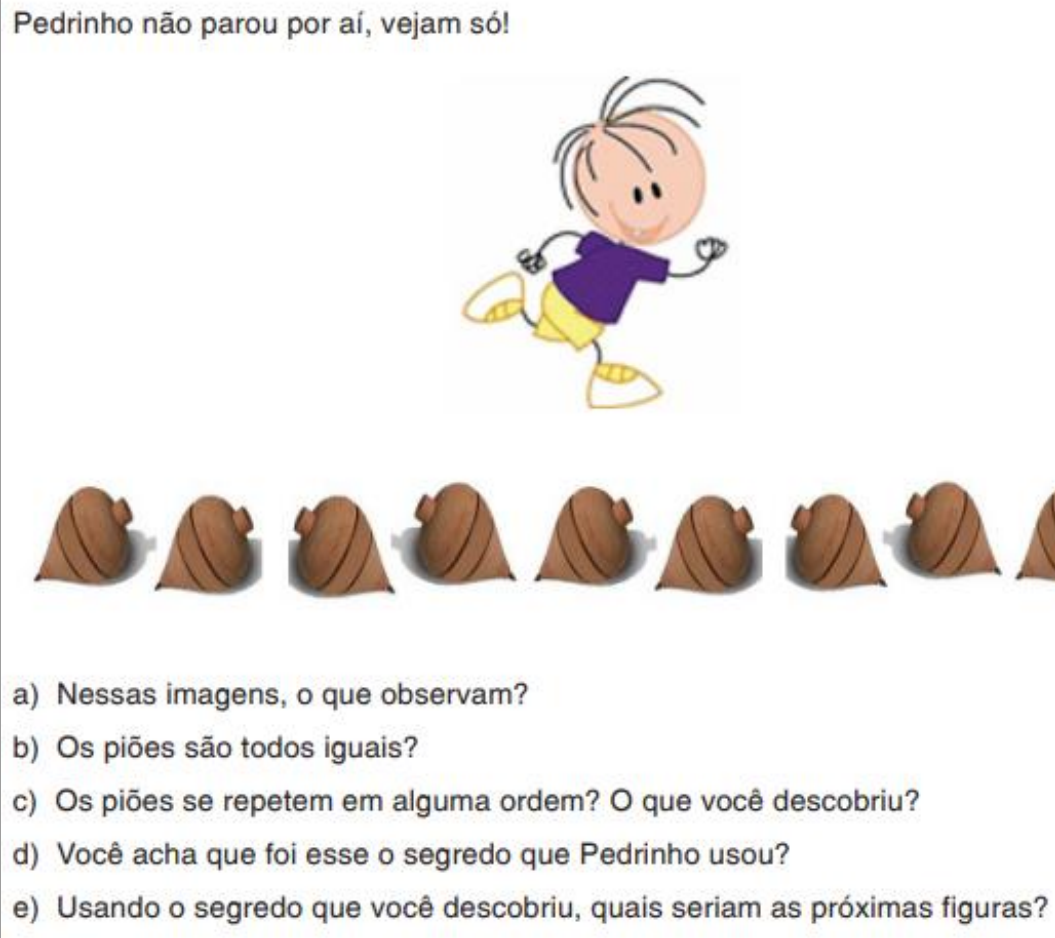

a) Nessas imagens, o que observam?

b) Os piões são todos iguais?

c) Os piōes se repetem em alguma ordem? O que você descobriu?

d) Você acha que foi esse o segredo que Pedrinho usou?

e) Usando o segredo que você descobriu, quais seriam as próximas figuras?

Figura 1: Exemplo de tarefa com sequência (SANTOS, LUVISON e MOREIRA, 2018, p. 84)

Para as autoras, na exploração da tarefa em questão, estima-se que "os alunos percebam 
que os quatro primeiros piões constituem o motivo de repetição. Assim, na sequência, há a repetição de dois motivos e o início do terceiro motivo" (SANTOS, LUVISON e MOREIRA, 2018, p. 84). Em uma possibilidade de vivência do que nos é apresentado aqui para a sala de aula, espera-se ainda que exista consenso de qual segredo Pedrinho adotou para a sequência. Além disso, se "a continuidade da sequência for na extremidade direita, a expectativa é que os alunos desenhem um pião virado para a esquerda e dois para a direita. Se essa continuidade for na extremidade esquerda, eles desenharão dois piões virados para a esquerda e dois para a direita" (SANTOS, LUVISON e MOREIRA, 2018, p. 84-85).

A aproximação com a temática pensamento algébrico e o processo de apropriação teóricometodológico-conceitual de como propor e desenvolver tarefas matemáticas que exijam dos estudantes este tipo de pensamento e, ao mesmo tempo, explore princípios estruturadores dos conceitos implícitos como modos de pensar (KIERAN, 2007), e não como conjunto de técnicas, é o desafio presente para que ocorram situações propicias para compreensão mais aprofundada da Matemática (PONTE e BRANCO, 2013).

Nos exemplos que trouxemos a título de ilustração ao leitor do que se entende por realizar, nos primeiros anos escolares, podem, aparentemente, parecer já estar presente em muitas das atividades docentes dos professores pedagogos no campo da Aritmética, contudo, de acordo com Ponte e Branco (2013, p. 136), para promover esse modo de pensar "é essencial proporcionar experiências que envolvem conjeturar, generalizar e justificar usando uma variedade de representações e linguagens". Sem dúvida, isso sinaliza para a importância que o professor representa no processo de aprendizagem do pensamento algébrico pelos estudantes, em que é

\footnotetext{
essencial que o professor tenha em atenção os aspetos matemáticos e didáticos relativos ao ensino da Álgebra de modo a preparar e concretizar situações de aprendizagem que visem esse desenvolvimento. A formação inicial de professores dos primeiros anos do ensino básico e de educadores de infância constitui um suporte fundamental para o desempenho futuro da sua atividade profissional, devendo contemplar experiências formativas que proporcionem o desenvolvimento do conhecimento necessário para esse desempenho. Por isso, é fundamental que os futuros professores, na sua formação inicial, reconheçam a importância do pensamento algébrico neste nível de escolaridade, valorizando a generalização, as relações e 0 uso de símbolos. A formação inicial deve ter ainda em conta que estes formandos, quando forem lecionar, serão colocados perante desafios relativos ao pensamento algébrico que, na sua maioria, nunca experimentaram enquanto alunos (PONTE e BRANCO, 2013, p. 136-137).
}

No caso brasileiro, indagamos: Como professores em exercício, os quais se licenciaram em programas de formação anteriores ao período de 2018, momento da inserção do pensamento 
algébrico no currículo dos Anos Iniciais, terão subsídios para fundamentarem suas ações com a unidade temática Álgebra?

Temos uma realidade presente e um desafio em curso a superar. Não é preciso ir muito longe para destacar que, dadas nossas experiências de pesquisas anteriores (SARTO e CIRÍACO, 2019) e da própria prática no curso de Pedagogia, existe falta de especificidade em conceituar 0 termo, bem como limitações no que respeita o repertório didático-pedagógico de professores e futuros professores com este perfil formativo. Dito isso, um caminho que encontramos, neste movimento do tempo presente, são as alternativas de trabalho colaborativo com professoras dos Anos Iniciais do Ensino Fundamental, em articulação com atividades de estudo coletivo, para implementação de práticas que podem vir à solucionar, em parte, alguns déficits formativos. Logo, temos na formação continuada de professores uma forte aliada frente as recentes mudanças curriculares.

Lima e Bianchini (2017, p. 206) destacam que mudanças no currículo influenciam "na formação inicial e continuada dos professores e nas metodologias que serão empregadas pelos mesmos, além de influenciar na elaboração dos currículos escolares e de materiais curriculares". Para tanto, é importante que aconteça um investimento em melhorias da formação inicial e continuada de professores para que as novas alterações possam ser desenvolvidas e trabalhadas por eles. Em outras palavras, "para que essas mudanças ocorram no âmbito da escola é preciso investir na formação de professores para a compreensão de conceitos algébricos de forma aprofundada, e entender quais atividades facilitam a apreensão dos alunos" (FREIRE, 2011, p. 18).

Nosso foco passa a ser aqui a formação continuada dos professores, tendo em vista as dificuldades e desafios emergentes quanto ao pensamento algébrico. Como alternativa, pautados nos moldes da colaboração; defendemos práticas de formação continuada com a adoção da metodologia Lesson Study, como é conhecida nos Estados Unidos. Traduzida como Estudos de Aula no Brasil, é uma metodologia originada no Japão, no final do século XIX, que se tornou recorrente em várias regiões do mundo, a partir da constituição de espaços coletivos de trabalho em torno da aprendizagem (FUJII, 2016; LEWIS, 2016; TAKAHASHI e McDOUGAL, 2018). Para tanto, de acordo com Quaresma e Ponte (2019, p. 369), nesta metodologia professores "estudam documentos curriculares e materiais de ensino e, com base nisso, planejam uma aula, que é realizada e objeto de reflexão aprofundada". 
Nesta proposta, professores coletivamente observam acontecimentos, refletem aprendizagens e desafios presentes na realização da tarefa proposta à turma, o que amplia 0 repertório didático-pedagógico do grupo e ainda possibilita encaminhamentos teóricometodológicos que representam alternativas ao trabalho docente, esta colaboração dá oportunidade para que o professor que ensina Matemática inove sua prática (FUJII, 2016).

Desse modo, entende-se que por justamente estarmos em momento de mudança na estrutura do currículo escolar, decorrente da inclusão de mais uma unidade temática no ensino de Matemática nos Anos Inicias, a metodologia Lesson Study possibilita a promoção de reflexões pertinentes ao direcionamento de como trabalhar questões ligadas à Álgebra no ciclo da alfabetização. Aprofundar os estudos e reflexões nesta direção representa um avanço na produção do conhecimento na medida em que é preciso que consigamos compreender melhor qual é a natureza do pensamento algébrico e de que forma abordá-lo desde o princípio da aprendizagem infantil.

Sendo assim, com a propositura de caracterizar pesquisas anteriores, na região Sudeste brasileira, realizamos um mapeamento de teses e dissertações acerca dos descritores de pesquisas pensamento algébrico e Lesson Study, centrados nos Anos Iniciais na perspectiva de contribuir com o avanço das discussões do debate teórico, bem como ainda possibilitar compreender o que dizem tais estudos e para onde nos orientam em termos de práticas possíveis e agendas de pesquisas abertas para o tempo presente. Entendemos que um estudo que se coloca frente à necessidade dos professores, ao incorporar Lesson Study como alternativa para a inclusão do pensamento algébrico é relevante e, para tanto, necessitamos correlacionar os termos ao descrever a produção do conhecimento da última década (2009-2019).

\section{Delineamento metodológico}

$\mathrm{Na}$ tentativa de demarcar a produção do conhecimento, particular na região Sudeste do Brasil - Estado de São Paulo -, direcionamos olhares e esforços no processo de empreender um mapeamento de teses e dissertações defendidas em programas de pós-graduação com um método de levantamento do tipo Estado da Arte. Posteriormente, fundamentamos as discussões na perspectiva da abordagem qualitativa, justamente porque este tipo de investigação permite ao pesquisador contato direto com a situação que estuda de modo que a organização de dados e catalogação de informações podem ser feitas e discutidas em um universo de significados 
(MINAYO, 2001). No que respeita ao método, pode-se afirmar que um trabalho nestes moldes busca

mapear e de discutir uma certa produção acadêmica em diferentes campos do conhecimento, tentando responder que aspectos e dimensões vêm sendo destacados e privilegiados em diferentes épocas e lugares, de que formas e em que condições têm sido produzidas certas dissertações de mestrado, teses de doutorado, publicações em periódicos e comunicações em anais de congressos e de seminários (FERREIRA, 2002, p. 258).

O que move o processo de constituição das informações coligidas e que serão analisadas é "a do não conhecimento acerca da totalidade de estudos e pesquisas em determinada área de conhecimento que apresenta crescimento tanto quantitativo quanto qualitativo, principalmente reflexões desenvolvidas em nível de pós-graduação" (FERREIRA, 2002, p. 258-259), ao que incluímos o respeito para com o que já fora produzido, em termos de nos situarmos no espaçotempo da produção do conhecimento em uma determinada área para, posteriormente, desenvolver ações de pesquisas no mesmo campo, contudo, tentando avançar em aspectos ainda pouco ou não explorados.

Neste contexto, a experiência do levantamento realizado exprime o percurso dos pesquisadores para com os últimos 10 anos (2009 - 2019). Para este fim, mapeou-se teses e dissertações defendidas em programas de pós-graduação stricto sensu do Estado de São Paulo com base nos descritores de pesquisa Pensamento Algébrico e Lesson Study. A localização dos cursos de mestrado e doutorado ocorreu a partir dos filtros presentes na Plataforma Sucupira ${ }^{3}$, em que foram selecionados programas da região Sudeste. Adotou-se, inicialmente, filtros da Área de Avalição Educação e Ensino e da Modalidade Acadêmico.

$\mathrm{Na}$ área de Educação, apareceram 28 registros de instituições com programas, em funcionamento e desativado. Em uma busca mais apurada, quando delimitamos os que tinham mestrado (ME) e doutorado (DO) em funcionamento, este número caiu para 22 cursos. Portanto, estes serão os quais verificaremos as teses e dissertações defendidas no período de 2009 a 2019, conforme consta na Tabela 1.

\footnotetext{
${ }^{3}$ Disponivel em https://sucupira.capes.gov.br/sucupira/public/consultas/coleta/programa/listaPrograma.jsf
} 
Tabela 1: Quantitativo de trabalhos (teses e dissertações) defendidos na área da "Educação" por instituição envolvendo os descritores de pesquisa adotados nos programas paulistas.

\begin{tabular}{l|c|c|c}
\multicolumn{1}{c|}{ INSTITUIÇÃO } & \multicolumn{2}{c|}{ PRODUÇÕES } & \multirow{2}{*}{ TOTAL } \\
\cline { 1 - 3 } \multicolumn{1}{c|}{ Programas } & MESTRADO & DOUTORADO & \\
\hline PUC (Campinas) & - & - & - \\
\hline PUC-SP (Currículo) & - & - & - \\
\hline PUC-SP (História, Política, Sociedade) & - & - & - \\
\hline UFSCar (São Carlos) & - & 1 & 1 \\
\hline UFSCar-SC (Educação Especial) & - & - & - \\
\hline UFSCar (Sorocaba) & - & - & - \\
\hline UMESP & - & - & - \\
\hline UNESP (Araraquara) & - & - & - \\
\hline UNESP (Marilia) & - & - & - \\
\hline UNESP (Presidente Prudente) & - & 1 & 1 \\
\hline UNESP (Rio Claro) & - & - & - \\
\hline UNICAMP & - & - & - \\
\hline UNICID & - & - & - \\
\hline UNIFESP & - & - & - \\
\hline UNIMEP & - & - & - \\
\hline UNINOVE & - & - & - \\
\hline UNISANTOS & - & - & - \\
\hline UNISO & - & - & - \\
\hline UNOESTE & - & - & - \\
\hline USF & - & - & - \\
\hline USP & - & - & - \\
\hline USP (Ribeirão Preto) & - & - & - \\
\hline TOTAL & - & - & - \\
\hline
\end{tabular}

Fonte: Elaboração dos Autores

Ao todo, foram encontrados 3 mestrados, destes 1 da UNICAMP; e 2 (dois) na USF. Ainda foram localizados 3 (três) doutorados, assim distribuídos: UFSCar, campus São Carlos (1); UNESP, campus Presidente Prudente (1); e USP (1).

Já em relação à área de Ensino, apareceram 17 registros em funcionamento e desativado. 
No processo de seleção dos cursos ativos, delimitando os que tinham mestrado (ME) e doutorado (DO), este número caiu para 10. A Tabela 2 ilustra os programas consultados.

Tabela 2: Quantitativo de trabalhos (teses e dissertações) defendidos na área de Ensino (Educação Matemática e Educação para Ciência) por instituição envolvendo os descritores de pesquisa adotados nos programas paulistas

\begin{tabular}{l|c|c|c|c}
\multicolumn{1}{c|}{ INSTITUIÇÃo } & \multicolumn{2}{c|}{ PRODUÇÕES } & \multirow{2}{*}{ TOTAL } \\
\hline Programas & MESTRADO & DOUTORADO & \\
\hline PUC (São Paulo) & 6 & 1 & 7 \\
\hline UFABC & 1 & - & 1 \\
\hline UNESP (Bauru) & - & - & - \\
\hline UNESP (Rio Claro) & - & - & - \\
\hline UNIAN & - & - & - \\
\hline UNICAMP (Ensino e História de Ciências & - & - & - \\
\hline da Terra) & & & - \\
\hline UNICAMP (Multiunidades em Ensino de & - & - & 1 \\
Ciências e Matemática) & & - & - \\
\hline UNICSUL & 1 & - & - \\
\hline UNIFESP & - & - & 9 \\
\hline USP & - & 1 & \\
\hline TOTAL & $\mathbf{8}$ & & - \\
\hline
\end{tabular}

Fonte: Elaboração dos Autores

Identificamos um total de 9 produções na última década, sendo 8 pesquisas de mestrado das instituições: PUC-SP (6); UFABC (1); e UNICSUL (1). Sobre os trabalhos de doutorado, temse 1 estudo vinculado à PUC-SP no mesmo período.

Como pudemos verificar, nas Tabelas 1 e 2, na última década (2009-2019) tivemos 15 pesquisas vinculadas aos programas tanto na área de Educação quanto na de Ensino do Estado de São Paulo. Dentre as produções, 11 são dissertações de mestrado e 4 são teses de doutorado. Ao encontrar estes estudos, o próximo passo fora a leitura dos resumos na perspectiva de localizar àquelas investigações que dizem respeito ao trabalho em turmas dos Anos Iniciais do Ensino Fundamental, com base nos descritores adotados por nós.

A Tabela 3 destaca o quantitativo dos estudos por descritor de pesquisa, independente da área de avaliação dos programas, conforme pode-se observar. 
Tabela 3: Quantitativo de pesquisas defendidas em programas das áreas de Educação e Ensino do Estado de São Paulo por descritor com foco nos anos iniciais (2009-2019)

\begin{tabular}{c|c|c}
\hline ANO & $\begin{array}{c}\text { LESSON } \\
\text { STUDY }\end{array}$ & $\begin{array}{c}\text { PENSAMENTO } \\
\text { ALGÉBRICO }\end{array}$ \\
\hline 2009 & - & - \\
\hline 2010 & - & - \\
\hline 2011 & - & - \\
\hline 2012 & - & - \\
\hline 2013 & - & - \\
\hline 2014 & - & - \\
\hline 2015 & 1 & - \\
\hline 2016 & - & 2 \\
\hline 2017 & 1 & 2 \\
\hline 2018 & - & 1 \\
\hline 2019 & - & 5 \\
\hline $\begin{array}{c}\text { Total por } \\
\text { descritor }\end{array}$ & 2 & \\
\hline $\begin{array}{c}\text { Total } \\
\text { trabalhos }\end{array}$ & & 7 \\
\hline
\end{tabular}

Fonte: Elaboração dos Autores

De acordo com a Tabela 3, podemos inferir que 7 das 15 produções localizadas no período têm relação direta com nosso tema de estudo: os Anos Iniciais. Tal dado destaca, ao que as informações sinalizam, a pouca produção em torno da temática no seguimento de ensino em questão.

Face às informações coligidas no mapeamento, obtivemos, na busca, 2 teses e 5 dissertações. As pesquisas foram defendidas nos programas das seguintes instituições: UFSCar, campus Sorocaba (1 D0); UNESP, campus Presidente Prudente (1 DO); USF (1 ME); PUC-SP (2 $\mathrm{ME})$; UFABC (1 ME) e UNICSUL (1 ME). Os dados mais detalhados serão apresentados na próxima seção. 


\section{A produção do conhecimento}

\subsection{0 que dizem as pesquisas sobre Lesson Study?}

No Quadro 1, a seguir, sintetizamos dados de identificação das produções científicas selecionadas.

Quadro 1: Produções com o descritor Lesson Study (2009-2019)

\begin{tabular}{|c|c|c|c|c|c|}
\hline Título & Autor & Orientador & Instituição & Nível & Ano \\
\hline $\begin{array}{c}\text { Docência } \\
\text { compartilhada na } \\
\text { perspectiva de } \\
\text { Estudos de Aula } \\
\text { (Lesson Study): um } \\
\text { trabalho com as } \\
\text { figuras geométricas } \\
\text { espaciais no } 5^{\circ} \text { ano. }\end{array}$ & $\begin{array}{l}\text { Grace } \\
\text { Zaggia } \\
\text { Utimura }\end{array}$ & $\begin{array}{l}\text { Profa. Dra. } \\
\text { Edda Curi }\end{array}$ & UNICSUL & Dissertação & 2015 \\
\hline $\begin{array}{c}\text { Aprendizagens e } \\
\text { desenvolvimento } \\
\text { profissional de } \\
\text { professores que } \\
\text { ensinam matemática } \\
\text { nos anos iniciais do } \\
\text { ensino fundamental no } \\
\text { contexto da Lesson } \\
\text { Study. }\end{array}$ & $\begin{array}{c}\text { Renata } \\
\text { Camacho } \\
\text { Bezerra }\end{array}$ & $\begin{array}{c}\text { Profa. Dra. } \\
\text { Maria Raquel } \\
\text { Miotto Morelatti }\end{array}$ & UNESP-PP & Tese & 2017 \\
\hline
\end{tabular}

Fonte: Elaboração dos Autores

O trabalho de Utimura (2015) teve como contexto de produção de dados a prática pedagógica de duas professoras que lecionavam em turmas de $5^{\circ}$ ano do Ensino Fundamental e uma docente especialista com licenciatura em Matemática, todas em exercício profissional em uma escola municipal de São Paulo (Capital). As colaboradoras da pesquisa eram participantes do Projeto de Docência Compartilhada, parte integrante do Programa Mais Educação São Paulo (2014) desenvolvido pela Secretaria Municipal de Educação de São Paulo (SME-SP), que consiste na parceria entre professores especialistas e polivalentes para pensar a melhor maneira de conduzir os estudantes na passagem dos Anos Iniciais para os Anos Finais do Ensino Fundamental, "inserindo um professor especialista para os $4^{\circ}$ e $5^{\circ}$ anos, atendendo e orientando os alunos durante as aulas, e um professor dos anos iniciais para os $6^{\circ}$ anos, visando intervenções didáticas e pedagógicas mais adequadas a esses alunos" (UTIMURA, 2015, p. 55). 0 objetivo principal foi analisar os potenciais deste projeto em relação às figuras geométricas espaciais com 
base no material didático proposto pela SME-SP.

Para alcançar o proposto, a autora se valeu de múltiplos instrumentos de coleta de dados, em uma abordagem qualitativa, como: análise documental, gravações em áudio, vídeos, fotografias, protocolos, diários de bordo, questionários, entrevistas e avaliações. Todo o processo de vivência, na experiência de Estudos de Aula, culminou na elaboração de um conjunto detalhado das contribuições da docência compartilhada às professoras envolvidas.

O "Projeto Docência Compartilhada na perspectiva de Estudos de Aula permitiu avanço das professoras no que se refere, principalmente, aos conteúdos matemáticos e à didática desses conteúdos" (UTIMURA, 2015, p. 150); As professoras "perceberam ao longo das aulas que quando as atividades são bem estudadas e trabalhadas, tanto as professoras quanto os estudantes se sentem mais seguros para desenvolverem e compreenderem as figuras geométricas espaciais" (p. 154).

No momento da dissertação, em que busca definir a estratégia metodológica Lesson Study, a autora menciona sua origem no Japão com a nomenclatura Jugyō Kenkyū, traduzida para o português como Pesquisa de Aula. Além disso, Utimura (2015) destaca outras terminologias em países como, por exemplo, Chile e Portugal. A definição, em consenso, com as práticas mencionadas é dada como "estratégia, recurso ou metodologia de formação de professores. Está focada em pesquisar a aula, a aprendizagem dos alunos e a prática docente, passando pelas etapas do planejamento, ação, avaliação e replanejamento das aulas" (UTIMURA, 2015, p. 52), sendo este um trabalho realizado em grupos colaborativos. A discussão "de" e "sobre" o trabalho nestes moldes é fundamentada em Elliot (2012), Felix (2010), Lorca (2009), Baptista et al. (2012), entre outros. Essa metodologia de formação de professores foi adaptada em quatro etapas: 1. Planejamento, dividido em duas fases: reuniões entre a professora pesquisadora e sua orientadora; e reuniões entre a professora pesquisadora e as duas professoras de $5^{\circ}$ ano; 2. Execução, desenvolvimento das atividades planejadas e seus respectivos registros; 3 . Reflexão e Avaliação, os registros foram analisados para reflexão e avaliação; e 4. Replanejamento, diante dos resultados as aulas foram aperfeiçoadas. O projeto perdurou pelo ano letivo de 2014 , momento em que foram apresentados cronogramas de março a agosto para as reuniões, desenvolvimento das atividades e, posterior, reflexão.

Dadas as práticas das sessões reflexivas, decorrentes dos estudos de aula, a pesquisadora afirma que as professoras aperfeiçoaram seus conhecimentos matemáticos em 
relação ao aspecto didático e específico de conteúdo. Se sentiram mais seguras para planejar e implementar inovações em suas aulas, o que foi permitido por seu desenvolvimento pessoal e profissional com base nas reflexões realizadas ao longo do trabalho em grupo. Em relação aos estudantes, conclui que evoluíram no sentido da aprendizagem das figuras geométricas espaciais, ressaltando a socialização entre eles durante as aulas como aspecto crucial, ao mesmo tempo em que desenvolveram aspectos pessoais, como autonomia e comunicação oral e escrita (UTIMURA, 2015).

Como principal resultado, Utimura (2015) afirma que os estudos de aulas é uma metodologia de formação de professores promissora, pois envolve o trabalho colaborativo e "os dados mostraram a potencialidade dessa metodologia" (p.137). Foi evidenciado que as docentes se sentiram mais seguras para dar aulas com maior conhecimento específico do conteúdo, que é adquirido nas etapas de "Reflexão e Avaliação", as quais influenciam diretamente no "Planejamento e Execução".

O segundo estudo mapeado diz respeito a tese de Bezerra (2017), intitulada "Aprendizagens e desenvolvimento profissional de professores que ensinam Matemática nos anos iniciais do Ensino Fundamental no contexto da Lesson Study", na qual a autora intencionou investigar e compreender "como professores que ensinam Matemática nos anos iniciais do Ensino Fundamental aprendem e quais os indícios de desenvolvimento profissional no contexto da Lesson Study" (p. 8) por meio de uma abordagem qualitativa e interpretativa. Para alcançar este objetivo, a autora subsidiou sua proposta de pesquisa com um grupo de dezesseis professores de $3^{\circ}$ e $4^{\circ}$ ano de uma escola municipal da rede de ensino de Foz do Iguaçu, interior do Estado de Paraná (PR), na divisa com Paraguai e Argentina. O trabalho colaborativo entre os participantes da ação foi dividido em dois grupos - um com foco na multiplicação e o outro, na divisão - para operacionalizar o processo de modo a alcançar as necessidades formativas dos professores e os objetivos do estudo. As informações pertinentes para a produção de dados foram angariadas a partir de narrativas, conversas informais, formulários, observações, gravações em vídeo e áudio, posteriormente transcritos, catalogados e analisados.

Para definir e utilizar o método neste contexto, a autora fez um levantamento teórico embasada em pesquisadores como: Perez Gómes e Soto Gómes (2011); Ponte et al. (2016); Aragão, Prezotto e Affonso (2015), entre outros, que auxiliaram na definição de Lesson Study como estratégia de problematização da ação em sala de aula, propondo a saída da prática, 
passagem pela teoria e volta à prática, ou seja, um momento de reflexão e compartilhamento entre pares com foco na ação docente, para melhor aprendizagem dos estudantes (BEZERRA, 2017). Para tanto, os professores desenvolveram tarefas a serem realizadas a partir de estudos sobre 0 tema, divisão e multiplicação, e as analisaram por meio de gravações que registraram as aulas e os encontros com os professores. O principal resultado da tese reside na evidência de que

\begin{abstract}
a formação continuada no contexto da Lesson Study é um forte aliado para sanar as defasagens de conteúdo matemático do professor que ensina matemática nos anos iniciais do ensino fundamental e a escola, um espaço propício para realizar tal formação. A pesquisa apontou que o trabalho com os professores no contexto da Lesson Study é bastante promissor no que tange ao desenvolvimento profissional e que seria bastante interessante se o mesmo fosse adotado no país, como acontece no Japão, até porque o investimento é pequeno e o resultado é positivo na aprendizagem do professor e, consequentemente, do aluno (BEZERRA, 2017, p. 173).
\end{abstract}

Ainda sobre as conclusões, a autora destaca que, durante os encontros, os professores tiveram momentos propícios ao desenvolvimento em relação à sua atuação com os estudantes, problematizando suas práticas, estudando mais a fundo a matéria e conceitos utilizados, adaptando as tarefas a partir de seus estudos, conversando entre os pares. Tudo isso resultou, ao que a experiência indica, maior autonomia, autoestima, reflexão e preocupação com 0 raciocínio de seus estudantes.

Sobre esse descritor, em síntese, é possível fazer a inferência de que durante as leituras, Lesson Study pode se apresentar com outras nomenclaturas, a exemplo: Estudos de Aula e/ou Pesquisa de Aula. Contudo, os trabalhos localizados no levantamento (UTIMURA, 2015; BEZERRA, 2017) convergem com a literatura desta metodologia de formação continuada de professores que ensinam Matemática.

\title{
4.2 0 que dizem as pesquisas sobre pensamento algébrico?
}

No Quadro 2 estão delineadas as produções científicas selecionadas.

A dissertação de Santos (2017, p. 7) buscou responder o seguinte questionamento a partir de uma abordagem qualitativa: "Quais indícios de pensamento algébrico podemos identificar nas estratégias de resolução de problemas, construídas por crianças de anos iniciais do Ensino Fundamental, a partir das percepções de regularidades em sequências e em relações de equivalência?". 
Quadro 2: Produções com o descritor "pensamento algébrico" (2009-2019).

\begin{tabular}{|c|c|c|c|c|c|}
\hline Título & Autor & Orientador & Instituição & Nível & Ano \\
\hline $\begin{array}{l}\text { O pensamento algébrico } \\
\text { nos anos iniciais do } \\
\text { Ensino Fundamental: a } \\
\text { percepção de } \\
\text { regularidades e o } \\
\text { pensamento relacional }\end{array}$ & $\begin{array}{c}\text { Carla } \\
\text { Cristiane Silva } \\
\text { Santos }\end{array}$ & $\begin{array}{l}\text { Profa. Dra. } \\
\text { Daniela Dias } \\
\text { dos Anjos }\end{array}$ & USF & Dissertação & 2017 \\
\hline $\begin{array}{l}\text { Álgebra nos Anos } \\
\text { Iniciais do Ensino } \\
\text { Fundamental: uma } \\
\text { análise do } \\
\text { conhecimento } \\
\text { matemático acerca do } \\
\text { Pensamento Algébrico }\end{array}$ & $\begin{array}{l}\text { Miriam Criez } \\
\text { Nobrega } \\
\text { Ferreira }\end{array}$ & $\begin{array}{l}\text { Prof. Dr. } \\
\text { Alessandro } \\
\text { Jacques } \\
\text { Ribeiro }\end{array}$ & UFABC & Dissertação & 2017 \\
\hline $\begin{array}{l}\text { Metanálise de pesquisas } \\
\text { brasileiras que tratam do } \\
\text { desenvolvimento do } \\
\text { pensamento algébrico } \\
\text { na escola básica (1994- } \\
\text { 2014) }\end{array}$ & $\begin{array}{l}\text { Flávio de } \\
\text { Souza Pires }\end{array}$ & $\begin{array}{l}\text { Profa. Dra. } \\
\text { Maria do } \\
\text { Carmo de } \\
\text { Sousa }\end{array}$ & UFSCar & Tese & 2018 \\
\hline $\begin{array}{l}\text { Pensamento Algébrico } \\
\text { no currículo do Ciclo de } \\
\text { Alfabetização: estudo } \\
\text { comparativo de duas } \\
\text { propostas }\end{array}$ & $\begin{array}{l}\text { José Roberto } \\
\text { de Campos } \\
\text { Lima }\end{array}$ & $\begin{array}{c}\text { Profa. Dra. } \\
\text { Barbara Lutaif } \\
\text { Bianchini }\end{array}$ & PUC-SP & Dissertação & 2018 \\
\hline $\begin{array}{l}\text { A comunicação escrita } \\
\text { matemática envolvendo } \\
\text { o pensamento algébrico } \\
\text { com futuras professoras } \\
\text { dos anos iniciais do } \\
\text { Ensino Fundamental }\end{array}$ & $\begin{array}{l}\text { Jane Lopes } \\
\text { de Souza } \\
\text { Goma }\end{array}$ & $\begin{array}{l}\text { Profa. Dra. } \\
\text { Ana Lúcia } \\
\text { Manrique }\end{array}$ & PUC-SP & Dissertação & 2019 \\
\hline
\end{tabular}

Fonte: Elaboração dos Autores

Para alcançar o que se propôs, foram desenvolvidas duas sequências de tarefas referentes aos temas abordados em sua questão norteadora - percepção de regularidades e relações de equivalência - para serem propostas em um $3^{\circ}$ ano, por uma professora da rede municipal de Nazaré Paulista (SP). A coleta de dados ocorreu a partir dos diários de campo da pesquisadora, áudio, gravações em vídeo da sala de aula, narrativas da professora colaboradora, discursos e registros dos estudantes. Neste trabalho, pensamento algébrico é definido como processo de generalização por parte dos estudantes, que envolve suas ideias matemáticas, bem como um modo de aferir significado às suas aprendizagens, pressupostos presentes em autores como Blanton e Kaput (2005). A medida que a discussão presente na dissertação avança, Santos 
(2017) cita os estudos de Vygotsky (2001) e Manson (1996) para enfatizar que em busca de assegurar o desenvolvimento do pensamento algébrico deve-se levar em conta os conhecimentos que os estudantes já possuem e sua capacidade de fazer representações simbolicamente, assim como elaborar hipóteses para a resolução de problemas.

A análise dos dados coletados, a partir do referencial teórico apresentado pela pesquisadora, evidenciou a importância da mediação pedagógica do professor ao instigar à reflexão e socialização dos estudantes, elementos que favorecem discussões matemáticas promotoras do pensamento algébrico. As estratégias de resolução dos estudantes mostraram vestígios do raciocínio algébrico nas tarefas de percepção de regularidades e pensamento relacional. As estratégias e aprendizagens foram sendo aprofundadas conforme os conhecimentos prévios apresentados, o que permitiu constatar o desempenho indicando, nas palavras da autora, que "um trabalho que se foca na aritmética generalizada pode desenvolver o pensamento algébrico de crianças ainda nos anos iniciais" (SANTOS, 2017, p. 152), enfatizando a contribuição de um contexto com tarefas potencializadoras.

Ferreira $(2017$, p. 6) propõe um estudo sob a perspectiva de responder "O que se entende por conhecimento matemático para o ensino do Pensamento Algébrico nos Anos Iniciais do Ensino Fundamental?", tendo em vista a fase de inserção de conteúdos da Álgebra no currículo brasileiro, diferente de outros países que já inseriram a temática e ressaltam sua importância no ciclo inicial da aprendizagem infantil. Ao fazer um levantamento sobre as definições de Álgebra e Aritmética, Ferreira (2017) conclui que há uma semelhança entre tais áreas no que respeita ao pensamento algébrico, uma vez que podemos compreendê-lo

\footnotetext{
como uma forma de estruturação do pensamento, que pressupõe a generalização de situações particulares a ideias gerais. Em síntese, ratificando a nossa própria compreensão, podemos dizer que: "a generalização está no coração do pensamento algébrico" (SCHILIEMANN, CARRAHER e BRIZUELA, 2007 apud FERREIRA, 2017, p. 30).
}

Com base em tal conceituação, para alcançar o objetivo do estudo, a autora adotou a abordagem qualitativa, com a fundamentação e apresentação dos dados de sua investigação no formato multipaper no decorrer dos capítulos da dissertação, com análise de documentos curriculares e dados coletados em um curso de extensão voltado à formação continuada de professores atuantes nos Anos Iniciais, intitulado "Matemática nos Anos Iniciais e o desenvolvimento do pensamento algébrico", guiado pelos participantes do projeto de pesquisa 
"Conhecimento Matemático para o Ensino de Álgebra: uma abordagem baseada em perfis conceituais", vinculado ao Programa Observatório da Educação (OBEDUC), financiado pela Coordenação de Aperfeiçoamento de Pessoal de Nível Superior (CAPES). O grupo foi formado, inicialmente, por vinte e cinco docentes; "tal formação foi oferecida nas dependências da Universidade Federal do ABC, campus de São Bernardo do Campo, São Paulo, nos meses de maio a julho de 2016. Contou com uma carga horária de 32 horas divididas em aulas presenciais (20 horas) e atividades à distância (12 horas)" (FERREIRA, 2017, p. 59).

Neste contexto, apresenta como objeto de pesquisa não apenas os documentos de orientação curricular, mas o saber dos professores em formação continuada sobre esse conteúdo em específico e três artigos de sua autoria que foram desenvolvidos a partir da experiência citada e se tornaram capítulos de sua dissertação, como meio de encontrar pontos de convergência que esclarecessem a pergunta norteadora.

Como resultado da análise dos documentos, aponta que existe uma intencionalidade para que o pensamento algébrico faça parte do currículo dos Anos Iniciais, mas isso ainda está em discussão, como é o caso da Base Nacional Comum Curricular - BNCC (BRASIL, 2016), que estava em suas versões preliminares quando do momento da realização do estudo (FERREIRA, 2017). Em contrapartida, na visão da autora, outros documentos, do campo da formação continuada de professores, como os cadernos do Pacto Nacional pela Alfabetização na Idade Certa — PNAIC apresentaram alguns elementos do conteúdo mesmo que de forma "rasa", sendo neles a primeira menção ao pensamento algébrico nos anos iniciais.

Em termos empíricos, os professores participantes da extensão, por sua vez, permitiram constatar que compreendem elementos metodológicos que promovem o desenvolvimento do pensamento algébrico nos estudantes - compreensão de que há várias maneiras de se chegar a um mesmo resultado, valorização do raciocínio, contextualização de atividades, entre outros —, no entanto, esses aspectos sozinhos não são suficientes à efetivação de práticas que promovam o desenvolvimento deste. Ferreira (2017) aponta, como conclusão, a necessidade de 0 conhecimento específico do conteúdo ser maior ou igual ao conhecimento do saber fazer, características dos saberes pedagógicos tão evidentes nos dados finais do estudo.

Sem dúvida, os resultados se apresentam como indicadores futuros à efetivação de outras propostas de estudos que sejam situadas no processo de apropriação do conhecimento especializado do professor que ensina Matemática nos Anos Iniciais. 
A tese de doutorado de Pires (2018) enfoca na Educação Básica como um todo, englobando os Anos Iniciais e Finais do Ensino Fundamental e o Ensino Médio. O autor procura, no desenrolar dos capítulos, postulados e argumentos presentes no trabalho, identificar, descrever e analisar

que indícios dos elementos que compõem o pensamento algébrico vêm sendo concebidos e descritos nas pesquisas brasileiras em Educação Matemática no período de 1994 a 2014, e, quais desses elementos têm sido priorizados no ensino da álgebra na educação básica escolar? (PIRES, 2018, p. 5).

Na busca de alcançar o objetivo, utiliza-se de revisão sistemática de investigações a partir da metanálise qualitativa, interrelacionando as leituras e construindo sínteses, baseado no paradigma indiciário de Ginzburg (1989). Em sua premissa inicial, defende que "o desenvolvimento do pensamento algébrico nas aulas de matemática ainda parte do pressuposto da ideia de generalização da aritmética e do processo de contagem para álgebra, ou seja, da particularidade para a generalidade e não o contrário" (PIRES, 2018, p. 10).

Quando foca na apresentação do pensamento algébrico, coloca em apreciação, na discussão levantada em sua tese, uma vasta lista de autores e significações para o termo. Ressalta, por fim, dois tipos de concepções: "a Álgebra como Aritmética Generalizada e a observação de regularidades e padrões para expressar generalização do pensamento" (PIRES, 2018, p. 78).

A partir de sua análise conclusiva, assim como das produções analisadas e conexões entre elas, é permitido confirmar sua premissa inicial de que o desenvolvimento do pensamento algébrico parte da particularidade para a generalidade no contexto da Educação Básica; e os elementos que têm sido priorizados a respeito do ensino da Álgebra são: a observação de regularidades e padrões; 0 desenvolvimento da habilidade de expressar a generalidade por meio da linguagem formal da álgebra simbólica, entre outros. Ou seja, o desenvolvimento do pensamento algébrico não é pleno tendo em vista que os docentes se baseiam, principalmente, nos currículos oficiais que, na maioria das vezes, apresentam a linguagem formal da Álgebra.

Lima (2018), em sua dissertação, realizou uma análise documental objetivando compreender as abordagens dadas sobre pensamento algébrico na Base Nacional Comum Curricular - BNCC (BRASIL, 2017) e nas Orientações Curriculares de Matemática para os Anos Iniciais - OCMAI (SÃO PAULO, 2014) quando se referem ao ciclo da alfabetização. A partir dos estudos, o autor define pensamento algébrico como "identificação, compreensão de padrões e 
regularidades em diversos contextos que possam ser generalizados, sem a necessidade de uma linguagem simbólica algébrica" (LIMA, 2018, p. 9), baseado em autores como Kaput $(1995,2008)$, Araújo (2008), Ribeiro e Cury (2015), Ponte e Branco (2013), entre outros.

No texto originário da pesquisa, é apresentada uma espécie de linha do tempo sobre 0 avanço dos estudos da Álgebra e do pensamento algébrico para o Ensino Fundamental, ciclo da alfabetização, destacando o que é colocado de forma implícita e explícita nos documentos como orientação para a ação efetiva do currículo prescrito.

A conclusão central é que as Orientações Curriculares de Matemática para os Anos Iniciais (OMAIC) de São Paulo não descrevem, de forma explícita, como desenvolver 0 pensamento algébrico nos primeiros anos. No entanto, alguns de seus aspectos foram identificados devido ao tema da pesquisa ser a busca também pela maneira implícita desta abordagem. Esta constatação comprova o motivo do professor, muitas vezes, não incluir 0 pensamento algébrico em seu planejamento de aula. Enquanto isso, constata que a Base Nacional Comum Curricular (BNCC) apresenta a Álgebra como uma unidade temática a ser contemplada nos Anos Iniciais, além de compará-la à concepção da Early Algebra4.

O último título localizado no mapeamento empreendido foi o de Goma (2019). Intitulado "A comunicação escrita matemática envolvendo o pensamento algébrico com futuras professoras dos anos iniciais do Ensino Fundamental", teve como questão norteadora "No desenvolvimento de uma sequência de questões, o que revela a comunicação escrita matemática de futuras professoras dos Anos Iniciais do Ensino Fundamental em relação ao pensamento algébrico?" (p. $6)$.

A coleta de dados foi realizada a partir de registros escritos por professoras dos Anos Iniciais em formação que participaram de uma oficina ofertada pela pesquisadora em parceria com "uma Instituição de Ensino Superior (IES) privada que oferece o curso de Pedagogia" (GOMA, 2019 , p. 49) e teve duração de duas horas; "a turma escolhida [foi] formada por alunas do período diurno do $8^{\circ}$ semestre" (p. 49), das quais 15 (quinze) puderam comparecer. Os escritos foram posteriormente examinados por meio da análise de conteúdo, tratados sob enfoque qualitativo.

Os constructos teóricos demarcados na pesquisa da autora sinalizam para o significado de pensamento algébrico na visão de Canavarro (2007) e Blanton e Kaput (2005). Destaca dois

\footnotetext{
${ }^{4}$ Early Algebra: área de pesquisa que estuda possibilidades de ensinar e aprender Álgebra desde os primeiros anos escolares.
} 
aspectos essenciais, "o primeiro é a generalização e a sua expressão gradual em sistemas de símbolos convencionais, o segundo corresponde ao raciocínio e ação sintaticamente orientada sobre as generalizações expressas em sistemas de símbolos organizados (GOMA, 2019, p. 38)".

Mais adiante, em sua dissertação, cita Ponte e Branco (2013), tendo em vista que seu foco centra-se na formação de professores:

\begin{abstract}
é fundamental que os futuros professores desenvolvam o seu pensamento algébrico e compreendam o papel da Álgebra nos primeiros anos. Para além disso, é importante que percebam a relação Álgebra com a Aritmética, de modo a promoverem na sua prática futura o pensamento algébrico de seus alunos (PONTE e BRANCO, 2013 apud GOMA, 2019, p. 40).
\end{abstract}

Em síntese, como meio de averiguar o desempenho das participantes da oficina em relação à escrita matemática, especificamente naquelas em que se destacam as representações acerca do pensamento algébrico, foi solicitado que resolvessem duas tarefas de uma sequência de questões, registrando os possíveis caminhos para sua resolução, para que pudessem ser identificados, nesse processo, a clareza, fundamentação, lógica e profundidade.

Ao findar a experiência formativa, evidenciou-se dados que mostraram níveis de conhecimento "médio" e "baixo" nessas dimensões da comunicação escrita, ou seja, pouco domínio sobre o conteúdo algébrico pelas professoras em formação inicial (GOMA, 2019). Face às conclusões, a autora enxerga

como promissora a possibilidade de pesquisas futuras desenvolvendo sequências de tarefas, tendo como referência as dimensões da comunicação escrita matemática como meio de fomentar a construção do Pensamento Algébrico, tanto na formação de professor, como em sala de aula (GOMA, 2019, p. 82).

A identificação dos estudos apresentados, ao longo deste tópico, oportunizou compreender que os trabalhos desenvolvidos no contexto brasileiro, pela ordem cronológica das produções, teve maior intensidade e incidência, mesmo que em baixa proporção, após as discussões de pensamento algébrico destacadas em cadernos de formação continuada de professores em programas do Governo Federal - a exemplo do PNAIC - e ainda pós-BNCC, muito embora em todas as pesquisas, mestrado e doutorado, são sinalizadas que as competências e habilidades ligadas à elementos da Álgebra são possíveis, desde sempre, de serem abordadas em contextos de problematização nas atividades do campo da Aritmética. Ainda é possível fazer a inferência de que, em termos quantitativos, tivemos mais pesquisas de mestrado quando 
comparadas com as teses.

\section{Conclusões: para onde os estudos nos orientam?}

Tivemos como intenção, ao longo deste artigo, refletir sobre o processo de inserção do pensamento algébrico nos primeiros anos escolares no Brasil, especificamente no ciclo inicial da alfabetização ( $1^{\circ}$ ao $3^{\circ}$ ano), razão pela qual optamos, no referencial teórico, em trazer exemplos de tarefas e perspectivas da literatura especializada na temática para pensar proposituras desta natureza. Além disso, como forma de fundamentar uma possível ação prática na universidade a qual estamos vinculados, propusemos, como foco do artigo, apresentar um mapeamento de teses e dissertações defendidas na última década (2009 a 2019) em programas de pós-graduação das áreas de Educação e Ensino presentes no Estado de São Paulo.

Os esforços empreendidos por nós, na intenção que tivemos no compartilhamento do trabalho em pauta, buscou definir os focos de investigações das produções localizadas no período circunscrito para o levantamento, seus objetivos, contextos, referenciais, como ainda os principais resultados. A busca fora guiada no sentido de percebermos, como objetivo do artigo, para onde estes estudos, anteriores, nos orientam quando pensamos, no campo da Educação Matemática nos Anos Iniciais, os descritores de pesquisas Lesson Study e Pensamento Algébrico, isso porque intencionamos implementar uma atividade de extensão e pesquisa nos moldes dos estudos de aula acerca da unidade temática Álgebra nos Anos Iniciais em uma escola pública de São Carlos $(\mathrm{SP})$.

Assim, o contato direto com a produção revelou características importantes, a saber:

- Os estudos que tratam de Lesson Study nos orientam que este é um contexto favorável para a formação continuada de professores, tendo em vista sua metodologia baseada na reflexão sobre a prática, mediada pela teoria, com foco na retomada de processos educativos que visem melhorar as ações em sala de aula. Ainda destacaram que tal abordagem centra-se na aprendizagem do professor, para que, aperfeiçoando sua atividade docente, consiga criar um ambiente problematizador e que favoreça o ensinoaprendizagem de seus estudantes e os processos de colaboração entre seus pares em contexto (UTIMURA, 2015; BEZERRA, 2017);

- As pesquisas que se referiram ao Pensamento Algébrico, de modo geral, evidenciam 
déficits formativos nas trajetórias do professor que ensina Matemática licenciado em Pedagogia. Apontam ser necessário um movimento de apropriação de referenciais teóricometodológico-conceitual sobre as propriedades algébricas para que se explore, de maneira mais exitosa, o que se entende por este tipo de pensamento e em como desenvolvê-lo com a criança dos Anos Iniciais. Destacam ainda ser preciso ter coerência e clareza nos dizeres de documentos que orientam as práticas curriculares, devido à recente inclusão deste tema e 0 forte embasamento destes nos programas de ensino oficiais para o planejamento de suas aulas. Outro aspecto que estas pesquisas identificaram que compromete 0 desenvolvimento do pensamento algébrico, nos estudantes e nos professores, é a visão de que a Álgebra só pode ser ensinada a partir de sua linguagem formal, o que é um equívoco, uma vez que o pensamento algébrico é indicado e evidenciado em várias atividades já realizadas e que precisam ser instrumentalizados para terem aspectos mais intencionais na formação e prática pedagógica (SANTOS, 2017; FERREIRA, 2017; PIRES, 2018; LIMA, 2018; GOMA, 2019).

Logo, dada a baixa proporção em termos de pesquisas em ambos descritores que adotamos e a não existência, no período e região mapeados, de trabalhos que correlacionem Lesson Study com processos de desenvolvimento do pensamento algébrico, entendemos ser esta uma possibilidade rica e promissora a ser explorada com professores dos Anos Iniciais nas ações de formação continuada, o que perspectivamos ocorrer na trajetória de pesquisa e nas ações que nosso grupo de estudos já vem realizando na região de São Carlos, desde março de 2019.

\section{Referências}

ARAGÃO, Ana Maria Falcão; PREZOTTO, Marissol; AFFONSO, Bianca Fiod. Reflexividades e parceria no cotidiano da escola: o método de formação docente Lesson Study. In: ENCONTRO NACIONAL DE EDUCAÇÃO, 12, 2015, Curitiba. Anais do XII EDUCERE: Formação de professores, complexidade e trabalho docente. Curitiba: PUC-PR, 2015. p. 16113-16124.

ARAÚJO, Elizabeth Adorno de. Ensino de álgebra e formação de professores. Educação Matemática Pesquisa, São Paulo, v. 10, n. 2, p. 331-446, jul./dez. 2008.

BAPTISTA, Mónica; PONTE, João Pedro da.; COSTA, Estela; VELEZ, Isabel; BELCHIOR, Margarida. Lesson study na formação de professores do $1^{\circ}$ ciclo do ensino básico. In: SEMINÁRIO DE INVESTIGAÇÃO EM EDUCAÇÃO MATEMÁTICA, 23, 2012, Coimbra, 2012. Actas do XXIII SIEM. Lisboa: APM, 2012, p. 127-138.

BEZERRA, Renata Camacho. Aprendizagens e desenvolvimento profissional de professores que 
ensinam Matemática nos Anos Iniciais do Ensino Fundamental no contexto da lesson study. 2017. 211f. Tese (Doutorado em Educação) - Faculdade de Ciências e Tecnologia. Universidade Estadual Paulista. Presidente Prudente.

BLANTON, Maria L.; KAPUT, James J. Characterizing a classroom practice that promotes algebraic reasoning. Journal for Research in Mathematics Education, v. 36, n. 5, p. 412-446, nov. 2005.

BRASIL. Ministério da Educação. Secretaria da Educação Básica. Base Nacional Comum Curricular: Educação Infantil e Ensino Fundamental. Brasília: MEC/SEB, 2017.

BRASIL. Ministério da Educação. Secretaria de Educação Fundamental. Parâmetros Curriculares Nacionais: Matemática. Brasília: MEC/SEF, 1997.

CANAVARRO, Ana Paula. O pensamento algébrico na aprendizagem da Matemática nos primeiros anos. Quadrante, Lisboa, v. 16, n. 2, p. 81-118. 2007.

ELLIOT, John. Lesson studies. Disponível em https://www.unicamp.br. Acesso em: 15, jan. 2020.

FALCÃO, Jorge Tarcísio da Rocha. Alfabetização algébrica nas Séries Iniciais. Como começar? Boletim GEPEM, Rio de Janeiro, n. 42, p. 27-36, fev./jul. 2003.

FELIX, Thiago Francisco. Pesquisando a melhoria de aulas de Matemática seguindo a proposta curricular do estado de São Paulo, com a metodologia da pesquisa de aulas (lesson study). 2010. 137f. Dissertação (Mestrado em Ciências Exatas e da Terra) - Centro de Ciências Exatas e de Tecnologia. Universidade Federal de São Carlos. São Carlos.

FERREIRA, Miriam Criez Nobrega. Álgebra nos Anos Iniciais do Ensino Fundamental: uma análise do conhecimento matemático acerca do pensamento algébrico. 2017. 147f. Dissertação (Mestrado em Ensino e História das Ciências e da Matemática) - Centro de Ciências Humanas e Naturais. Universidade Federal do ABC. Santo André.

FERREIRA, Norma Sandra de Almeida. As pesquisas denominadas "Estado da Arte". Educação \& Sociedade, Campinas, v. 23, n. 79, ag. 2002.

FIORENTINI, Dario; MIORIM, Maria Ângela; MIGUEL, Antonio. Contribuições para um repensar... a educação algébrica elementar. Pro-Posições, Campinas, v. 4, n. 1, p. 78-91, mar. 1993.

FREIRE, Raquel Santiago. Desenvolvimento de conceitos algébricos por professores dos Anos Iniciais do Ensino Fundamental. 2011. 181f. Tese (Doutorado em Educação) - Faculdade de Educação. Universidade Federal do Ceará. Fortaleza. 2011.

FUJII, Toshiakira. Designing and adapting tasks in lesson planning: a critical process of Lesson Study. ZDM Mathematics Education, Dordrecht, v. 48, n. 4, p. 411-423, 2016.

GINZBURG, Carlo. Mitos, emblemas, sinais. Tradução de Federico Carotti. 2 ed. São Paulo: Companhia das Letras, 1989.

GOMA, Jane Lopes de Souza. A comunicação escrita matemática envolvendo o pensamento algébrico com futuras professoras dos Anos Iniciais do Ensino Fundamental. 2019. 92f. 
Dissertação (Mestrado em Educação Matemática) - Faculdade de Ciências Exatas e Tecnologias. Pontifícia Universidade Católica de São Paulo. São Paulo.

KAPUT, James. A research base supporting long term Algebra reform? In: ANNUAL MEETING OF NORTH AMERICAN CHAPTER OS INTERNATIONAL GROUP FOR THE PSYCOLOGY OF MATHEMATICS EDUCATION, 17, Columbus. Whasigton, 1995, p. 2-26.

KAPUT, James. What is Algebra? What is algebraic reasoning? In: KAPUT, James; CARRAHER, David William; BLANTON, Maria (Ed.). Algebra in the early grades. New York: Routledge, 2008, p. 5-18.

KIERAN, Carolyn. Developing algebraic reasoning: the role of sequenced tasks and teacher questions from the primary to the early secondary school levels. Quadrante, Lisboa, v. 16, n. 1, p. 5-26, 2007.

LEWIS, Catherine. How does lesson study improve mathematics instruction? ZDM Mathematics Education, Dordrecht, v. 48, n. 4, p. 571-580, 2016.

LIMA, José Roberto de Campos. Pensamento algébrico no currículo do Ciclo de Alfabetização: estudo comparativo de duas propostas. 2018. 80f. Dissertação (Mestrado em Educação Matemática) - Faculdade de Ciências Exatas e Tecnologias. Pontifícia Universidade Católica de São Paulo. São Paulo.

LIMA, José Roberto de Campos; BIANCHINI, Bárbara Lutaif. A álgebra e o pensamento algébrico na proposta de Base Nacional Curricular Comum para os Anos Iniciais do Ensino Fundamental. Revista de Produção Discente em Educação Matemática, São Paulo, v. 6, n. 1, p. 197-208, jan./jun. 2017.

LORCA, Arturo Mena. A. El estudio de clases japonés en perspectiva. In: JORNADAS NACIONALES DE EDUCACIÓN MATEMÁTICA, 23, 2007, Viña del Mar. Actas del XIII JNEM. Viña del Mar: Sociedad Chilena de Educación Matemática, 2007, p. 1-7.

MASON, John. Expressing generality and roots of algebra. In: BEDNARZ, Nadine; KIERAN, Carolyn; LEE, Lesley. (Ed.). Approaches of algebra: perspectives for research and teaching. Dordrecht: Kluwer Academic Publishers, 1996, p. 65-86.

MINAYO, Maria Cecilia de Souza. (Org.). Pesquisa social: teoria, método e criatividade. Petrópolis: Vozes, 2001.

NACARATO, Adair Mendes; CUSTÓDIO, Iris Aparecida. (Org). O desenvolvimento do pensamento algébrico na educação básica: compartilhando propostas de sala de aula com 0 professor que ensina (ensinará) Matemática. Brasília: SBEM, 2018.

PEREZ GÓMEZ, Angel; SOTO GÓMEZ, Encarnación. Lesson Study: la mejora de la práctica y la investigación docente. Cuadernos de Pedagogía, v. 417, p. 64-68, 2011.

PIRES, Flávio de Souza. Metanálise de pesquisas brasileiras que tratam do desenvolvimento do pensamento algébrico na Escola Básica (1994-2014). 2018. 138f. Tese (Doutorado em Educação) - Centro de Educação e Ciências Humanas. Universidade Federal de São Carlos. São Carlos. 2018. 
PONTE, João Pedro da; BRANCO, Neusa. Pensamento algébrico na formação inicial de professores. Educar em Revista, Curitiba, n. 50, p. 133-155, out./dez. 2013.

PONTE, João Pedro da; QUARESMA, Marisa; PEREIRA, Mata Joana; BAPTISTA, Mónica. 0 Estudo de Aula como processo de desenvolvimento profissional de professores de Matemática. Bolema, Rio Claro, v. 30, n. 56, p. 868-891, set./dez. 2016.

QUARESMA, Marisa; PONTE, João Pedro da. Dinâmicas de reflexão e colaboração entre professores do $1{ }^{\circ}$ ciclo num estudo de aula em Matemática. Bolema, Rio Claro, v. 33, n. 63, p. 368-388, abr. 2019.

RIBEIRO, Alessandro Jacques; CURRY, Helena Noronha. Álgebra para a formação do professor: explorando os conceitos de equação e função. Belo Horizonte: Autêntica, 2015.

SANTOS, Carla Cristiane Silva; LUVISON, Cidinéia da Costa; MOREIRA, Kátia Gabriela. A construção do pensamento algébrico no Ensino Fundamental l: possíveis trabalhos para a percepção de regularidades e de generalizações. In: NACARATO, Adair Mendes; CUSTÓDIO, Iris Aparecida. (Org). O desenvolvimento do pensamento algébrico na educação básica: compartilhando propostas de sala de aula com o professor que ensina (ensinará) Matemática. Brasilia: SBEM, 2018, p. 71-196.

SANTOS, Carla Cristina Silva. O pensamento algébrico nos Anos Iniciais do Ensino Fundamental: a percepção de regularidades e o pensamento relacional. 2017. 182f. Dissertação (Mestrado em Educação) — Universidade São Francisco. Itatiba.

SÃO PAULO (Estado). Secretaria de Estado da Educação. Coordenadoria de Gestão da Educação Básica. Orientações Curriculares do Estado de São Paulo - Anos Iniciais do Ensino Fundamental: Matemática. São Paulo: SEE/CGEB, 2014.

SARTO, Beatriz; CIRÍACO, Klinger Teodoro. Professores que ensinam Matemática e 0 desenvolvimento do pensamento algébrico em um contexto de lesson study nos Anos Iniciais. In: Colóquio Alagoano de Educação Matemática nos Anos Iniciais, 1, 2019, Maceió. Anais do I CAEMAI: Desafios da formação do pedagogo e sua atuação nas aulas de Matemática. Maceió: UFAL, 2019, p. 1-3.

SCHLIEMANN, Analúcia Dias; CARRAHER, David William; BRIZUELA, Bárbara. Bringing out the algebraic character of arithmetic: from children's ideas to classroom practice. Mahwah: Lawrence Erlbaum Associates, 2007.

TAKAHASHI Akihiko; McDOUGAL, Thomas. Collaborative lesson research (CLR). In: QUARESMA, Marisa; WINSLØW, Carl; CLIVAZ, Stéphane; PONTE, João Pedro da; SHÚILLEABHÁIN, Aoibhinn Ní; Takahashi; Akihiko. (Ed.). Mathematics lesson study around the world: theoretical and methodological issues. Germany, Springer, 2018, p. 143-152.

UTIMURA, Grace Zaggia. Docência compartilhada na perspectiva de Estudos de Aula (Lesson Sutdy): um trabalho com as figuras geométricas espaciais no $5^{\circ}$ ano. 2015. 161f. Dissertação (Mestrado em Ensino de Ciências e Matemática) — Universidade Cruzeiro do Sul. São Paulo.

VYGOTSKY, Lev Semenovich. A construção do pensamento e da linguagem. Tradução de Paulo Bezerra. São Paulo: Martins Fontes, 2001. 